\title{
Chinese Folk Culture Practical Teaching and Field Investigation
}

\author{
Qianwei Jin \\ School of arts and culture communication \\ Guangxi University of Science and Technology \\ Liuzhou, China 545006
}

\author{
Xiaofeng Chen \\ School of arts and culture communication \\ Guangxi University of Science and Technology \\ Liuzhou, China 545006
}

\begin{abstract}
Chinese folk culture pays much attention to field investigation because it is very important to help students to learn field research through practical teaching. The author believes that we can guide students to clearly understand the connotation of the field investigation through the case-based teaching method in the classroom; make them to grasp field research methods by using training for folk culture of food and clothing in and out of class; guide students to figure out the procedures and priorities of the field investigation by adopting the problem-based learning; lead students to conduct in-depth field investigations in representative areas to understand the value and difficulties of the investigation, and help them to better protect the representative folk-custom culture through empirical investigation for folk custom tours.
\end{abstract}

Keywords-Chinese folk culture; practical teaching; field investigation

\section{INTRODUCTION}

Chinese folk culture is the folk knowledge and skills in folk dimension of historical inheritance, of which the life form mainly exists in rural areas. The more significant typical folklore forms preserved as daily life are in remote places such as villages in high mountains and at end of rivers. Folk customs closely related to eating, drinking and living are much loved by students. In particular, folk-custom tours springing up with the development of the times have aroused great interest of students. When it comes to carrying out cultural surveys, most of the students prefer to look for tourist places with landscapes for research since students think they can take advantage of field surveys to see beauty, which is very fantastic. It is believed that the real field investigation should be based on a scientific and rigorous attitude and use effective investigation methods to obtain valuable information, so it is necessary to guide students to regard fieldwork dialectically. Especially in classroom teaching, we need to create a positive atmosphere for scientific research to cultivate more reserve personnel for

Project Fund: Practical Application Project of Typical Teaching Methods of Guangxi University of Science \& Technology in 2016 (Practice and Application of Typical Teaching Methods of <Chinese folk customs> (Class A, No. 4); Project of Undergraduate Teaching Reform of Higher Education in Guangxi in 2017 (Teaching Innovation of "Chinese Culture" Courses of MTCSOL under the Background of "the Belt and Road") (No.: 2017JGB285). research

\section{Classroom Teaching Uses TyPicAl CASE METHOD TO HELP STUDENTS CONSTRUCT A SCIENTIFIC OUTLOOK ON FOLKLORE}

In ancient China, etiquette is different between custom. It is believed that folk culture without education could not be considered as elegant things. Until the modern times, social mainstream culture began to promote the folk culture. They hope the grassroots people who created the folk culture could become the backbone for the prosperity of the nation, which is a subversive understanding of folk culture. Classroom teaching should combine folk-custom historical materials to naturally guide students to establish a correct outlook of folk custom. Especially the case teaching method should be effective used to make students truly recognize the importance of folk culture.

First, folk culture is rooted in the civil public and has a cultural gene that recognizes the pattern of social life. It is difficult to reach such an understanding is quite difficult, because simple preaching will not give people a deep impression as well as touch the students' hearts. The real society still regards the public culture as lower-class culture under the elite culture. To tell students correctly understanding of the folk culture enjoys inestimable important value needs attention and enough data to prove The author thinks that the use of typical cases can play an empirical role. First of all, the author recommends Benedict's "chrysanthemum and knife" to students, and analyze the profound influence of special cultural model on the Japanese people based on the survey data. We should let students tirelessly collect and organize relevant information and understand that the cultural model rooted in the hearts of the people can both influence the daily life and have the function of self-preservation due to the unique emotional sustenance and long-term habits, which is presented as special folk culture relying on the efforts of individual students and the results of collective discussions. Thus, it is explored that there is another explanation for Japan's repeated refusal to admit the heinous crimes it committed after World War II. Its root lies in the bad quality of Japan's public psychology, which not only wants to maintain a strong and proud external image by avoiding historical responsibility, but also cannot 
hide their innermost feelings of fragility and inferiority. Then it can be seen from the various behaviors of turning backward of Japan after the war collected and arranged by students that the role of folk culture for the collective and the country to build social life model is very important. Therefore, mystery of folk culture can only be found through field investigation.

Second, we enumerates representative scholars of both Chinese and foreign countries to set an example for students to conduct in-depth fieldwork. There are many ethnic groups in our country and the cultures they create are diverse, so each region has various kinds of cultures worthy of lifelong research. The field investigation we talk about here mainly takes the South as an example. Chinese and foreign creative academics attach great importance to first-hand information, so they spare no effort to conduct investigation deep in valuable areas. Because from the time dimension, the more complete preservation of the original cultural model is earlier, only in the inaccessible villages it will be preserved more complete. The villages where we carry out investigation [1] basically are places with inconvenience traffic, blocking of the mountains and rivers, dense forests, and beasts. Such field investigation is not only extremely difficult, but also sometimes dangerous. The typical cases include famous Chinese folk culture scholar Mr. Fei Xiaotong, who went to Dayao Mountain in Guangxi with his wife shortly after marriage in 1930's. They did not expect to fall into the trap, so his wife was anxious to call rescuers but finally swallowed by floods. The descendants who know the matter all feel regret. We can tell students through this case that the field investigation is definitely not tour and sightseeing. Only crossing mountains and river to go deep to the farm land is it possible to get valuable information. Guangxi folk culture has attracted many foreign scholars. Experts from Australia, Japan and Southeast Asian countries come here to survey from time to time. The bitter of field investigation can be known by carefully studying their investigation experience. In order to reach the ideal place for investigation, they spare no efforts to travel long distances and always have no time to rest because of hurry trip, so they sleep in the mountain and stay overnight leaning on trees in the mountains, so that they can reach the destination as soon as possible at dawn. It is also important to be familiar with the local people, requiring us to spend enough time living with them [2], and thus we can get the results of the survey we want. It is exactly the results obtained by these scholars who emphasize evidence through investigation that can attract people's attention and the papers and monographs published by them also attract much attention. Through case teaching, students understand what the real field investigation is.

\section{ADOPTING THE PROBLEM-BASED LEARNING TO TRAIN STUDENTS TO MASTER THE STUDY OF FOLK CUSTOMS IN AND OUT OF CLASS}

They can learn folklore research methods in class and apply in practical activities inside and outside the class. The author believes that it is more important to carry out relevant research both inside and outside the campus and train students step by step to master the research methods of folk custom. Formal research projects should be arranged after the students getting familiar with it gradually.

First, dietary folk culture is an ideal project to train students to research. First of all, the canteens in school that meet students dining are filled with foods from different regions, both including the local representative snacks and nationwide representative dishes. Another important point is to facilitate students to carry out investigations. The southern diet highlights the dominance of rice, adding meat dishes like chicken, duck and beef, and supplemented with vegetables of cabbage and mustard, which does not pursue the taste of salt and uses a little spicy material with moderate taste; students find that the methods of cooking rice is various after comparison. The South regards rice as the various kinds of main food that fills the stomach, such as frying rice accompanied by camellia and making rice into rice noodles. Among them, the more influential are the Guilin rice noodles and Liuzhou river snail rice noodle. Both rice noodles are very similar, and the main difference is the condiments. River snails rice noodle is dipped in boiled river snail, coupled with unique acid condiment, forming a distinctive regional local snacks. It can be known through students' long-term eating and targeted investigation that the diet is good enough for local dietary flavors. In addition to the local diet, it is also possible to investigate other regional diet, such as how the cooked wheaten food in the north are modified to meet the dietary needs of the South and what types of cooked wheaten food are accepted by the south. It is found through the investigation that the northern noodles are transformed into the southern stewed noodles, into which you can add eggs, meat, and vegetables, etc. Northern fried cake is changed to the southern pancake, which can be made into vegetarian or meat pie to meet the tastes of students in the North as well as that of Southern students. This conclusion needs the help of questionnaires and statistics of field visits to get representative data.

Second, folklore research of costumes is extremely convenient. Students from all corners of China are gathered in each university. Different garments from all over the country have become extremely convenient object for investigation. In particular, all ethnic groups in China have distinctive national costumes. This paper mainly studies the costumes of the southern peoples. First of all, women's headwear and outerwear of Zhuang, Yao, Miao and other peoples are displayed in the classroom. Many students find it very novel and most of them think they are very beautiful, but it is hard to distinguish them. The author holds that now that students are interested in the research, we should take the advantage to immediately arrange students to search the materials in hand and online literature after the class to find out what are the external characteristics of clothes of the three peoples, what philosophical implications are contained and what kind of aesthetic awareness is reflected. At the same time, students familiar with the three peoples are selected to be interviewed. Through this series of practical operation, students learn the methods to study clothing as well as enjoy the talents and wisdom created by all ethnic groups. It should be said that such research training is successful because it complete the learning objective of folk 
culture investigation conveniently and discriminate the modern function of garments is mainly the beauty. It particularly exercises everyone's ability of communication and let students experience the diversity of our multi-ethnic culture, so we should treasure the distinctive characteristics of culture and absorb the strong point of culture of all ethnic groups to jointly promote the development of national culture.

\section{GOING DEEP INTO REPRESENTATIVE REGIONS TO CARRY OUT FIELD SURVEY TO HELP STUDENTS GET FAMILIAR WITH FIELD INVESTIGATION}

Through teachers' explanation in class and extracurricular practical training, especially the investigation combining the food culture inside and outside the school with costumes and clothing culture help students master a certain field survey methods. According to the research data submitted by students, the author determined to lead them go out of the campus, to carry out field research activities in representatives regions.

First, the research object needs to be familiar areas, which mainly train students to grasp the focus of the investigation and solve all kinds of puzzles. The author once led the students to visit the historical cattle-worship in the Zhuang minority region. From the source of culture, the cattle are the main sustainer of rice culture in the South. Under the condition of low productivity, people can only rely on the relatively strong and moderate farm cattle to finish the necessary labor such as planting, producing and storing. Since the cattle is easy to feed and serves as a helpful assistant for human beings, it has a special status in most ethnic groups in the south. For example, the common last names Mo and Huang of Zhuang people are related to cattle. Therefore, some scholars think that cattle are a totem of Zhuang people, which is reasonable. In order to maintain the durability of production and life, Zhuang peasants reached a consensus on the protection of farm cattle based on selfexperience, which is a summary of life experiences. The importance of cattle is obvious in ancient mythology. In order to help cattle maintain better physical strength, people think necessary protection need to be given to cattle and the best protection is the sacrificial ceremony from the heart. The annual festival of cattle is held for birthday of cattle and the traditional festivals for cattle has been inherited as a typical folk culture today. In addition to leading students to observe the sacrificial ceremony, the more important goal of the author is to guide students to go deep into the farm, investigate the living conditions of cattle in reality and fully realize the concept of ecological sustainable development of people reflected in the protection of the cattle.

Second, at present, all kinds of folk-custom tours are very hot, so we should lead students to take a dialectical view of participation in folk-custom development activities and make necessary investigations. Folk culture has the original ecological way of life, reflecting the wisdom of people creating all things of life with the characteristics of meeting the curiosity, so many places actively develop folk culture tour with regional characteristics. On the positive side, the resurrection, refinement and enlargement of representative folk culture has a good side, which not only inherits the folk culture, but also well protects them in the time with very rich culture. In the context of growing urbanization, developing representative folk culture through tourism is also a kind of protection measure. However, everything has its two sides. There are also a large number of people who manufacture folk culture in a rough way or make excessive transformation to cater for tourists' tastes. Therefore, leading students to investigate in some folk-custom culture attractions, we cannot be satisfied with skimming the surface. Instead, we should correctly learn the theoretical knowledge of folklore heritage and protection and at the same time possess a very rich knowledge of regional folk culture to examine whether the valuable folk culture is really protected or just decorated all in the same way. Students should combine their own knowledge of folklore to help local authorities and the villagers put the valuable folk culture in their tourism resources to present its living conditions. Then they spread the representative folk culture in the form of folk customs tours to serve the inheritance and protection of folk culture.

\section{CONCLUSION}

Teaching of Chinese folk culture practice is inseparable from field investigation, so we should guide students to choose the appropriate project to carry out investigations by using the techniques learnt in class, make clear the key and difficult points and the value of investigations and provide good service for the protection of live folk-custom.

\section{REFERENCES}

[1] Geertz , Clifford. "Thick Description: Toward an Interpretive Theory of Culture." C.Geertz, The Interpretation of Culture, NewYork :Basic Books, 1973, P22

[2] [America]Akhil Gupta, James Ferguson. Anthropological Locations Boundaries and Grounds of a Field Science. Tr. Luo Jianjian et al. Beijing: Huaxia Publishing House, 2005: 39. 